\title{
Subtrochanteric Femur Fracture in Neonates: A Rare Complication after Breech Presentation
}

\author{
Sahil Singla ${ }^{1}$, Rohit Sharma ${ }^{2}$, Rajan Sharma ${ }^{3}$, Ranbir S Bawa ${ }^{4}$, Arshpreet Singh ${ }^{5}$, Navpreet S Sidhu ${ }^{6}$, Satinderpal K Satti ${ }^{7}$ \\ Arshpreet S Dhillon ${ }^{8}$
}

\begin{abstract}
Fetus born in breech presentation are commonly delivered via cesarean section which is necessary to prevent trauma, and this extraction by operative maneuver can rarely lead to trauma and may result in femur fracture. But delivery of breech via vaginal route leads to various complications such as fractures. Femur fracture although being relatively a rare complication one of the most common fractures of the lower extremity presenting in newly born babies. In our case, 39-week mature fetus with weight 3,300 g breech presentation delivered by cesarean section presented with subtrochanteric femur fracture left side. A complete healing of the fracture, without any sequelae, was noted when the patient was simply immobilized with hip in flexion, abduction, and external rotation. The possibility of accidental injuries and traumatic complications are significantly reduced in cesarean section, especially in breech delivery when compared with vaginal delivery, but it does not completely eliminate the possible birth injuries and thus fractures of the newborn. So, clinicians must check for fractures even after cesarean section in breech presentation.

Keywords: Breech presentation, Cesarean section, Subtrochanteric femur fractures.

Journal of Orthopedics and Joint Surgery (2020): 10.5005/jp-journals-10079-1028
\end{abstract}

\section{INTRODUCTION}

Less than $1 \%$ of all live births have birth injuries presenting during the childbirth process. ${ }^{1}$ The spectrum of birth injuries can present as a simple bruise, swelling, forceps scar, or it can be as a severe as the loss of nerve and motor function and rarely, a fracture. Vaginal breech deliveries are thought to be responsible for around threequarters of all long bone fractures during birth. ${ }^{2}$ The vaginal breech birth can also lead to traumatic outcome as a fracture of the femur although it is considered a rare entity. ${ }^{3}$ Cesarean section reduces the risk of fracture of long bones but does not completely eliminate its possibility. ${ }^{4}$ Those newly born babies who are diagnosed with a fracture in the first week of life, in the absence of any other known post-natal trauma, are considered to have suffered a birth fracture, as it is well known that difficult birth requires considerable traction that can result in neonatal femur fractures. ${ }^{5}$ We here present a case of newborn with left femur subtrochanteric fracture because of breech presentation.

\section{Case Description}

This is a case of neonate born at 39 weeks with birth weight of 3,300 $\mathrm{g}$ with breech presentation delivered by cesarean section. The mother is a 33-year-old primigravida with no past history of uterine surgery and no gestational problems. Through lower segment cesarean section, the baby was delivered without any intraoperative complication. No cracking sound was heard, and baby cried immediately after birth. Thorough clinical examination was performed, and all routine laboratory test were performed which showed no abnormality.

On day 1 , the neonate was doing well but on day 2 the neonate became irritable, disinterested in feeding, and afebrile. On clinical examination, the left lower extremity was swollen, shorter than right side, and painful passive movements with tenderness was present with normal distal pulses. X-ray of left lower limb was done

\begin{abstract}
${ }^{1}$ Department of Orthopaedics, Sri Guru Ram Das University of Health Sciences, Amritsar, Punjab, India

${ }^{2-4}$ Department of Orthopaedics, Sri Guru Ram Das Medical College, Amritsar, Punjab, India

${ }^{5}$ Department of Orthopaedics, Sri Guru Ram Das University of Health Sciences, Jalandhar, Punjab, India

${ }^{6}$ Department of Orthopaedics, Sri Guru Ram Das University of Health Sciences, Barnala, Punjab, India

${ }^{7}$ Department of Orthopaedics, Sri Guru Ram Das University of Health Sciences, Malerkotla, Punjab, India

${ }^{8}$ Department of Orthopaedics, Sri Guru Ram Das Medical College, Ludhiana, Punjab, India

Corresponding Author: Rajan Sharma, Department of Orthopaedics, Sri Guru Ram Das Institute of Medical Sciences and Research, Amritsar, Punjab, India, Phone: +91 9501029982, e-mail: sharmarajan29@yahoo. com

How to cite this article: Singla S, Sharma R, Sharma $R$, et al. Subtrochanteric Femur Fracture in Neonates: A Rare Complication after Breech Presentation. J Orth Joint Surg 2020;2(2):79-81.
\end{abstract}

Source of support: Nil

Conflict of interest: None

(anteroposterior and lateral view) showing subtrochanteric femur fracture with proximal segment undergoing flexion, abduction, and external rotation (Fig. 1). On X-ray, bone structure and mineralization were found to be normal, and other possibilities of fracture were also ruled out such as osteogenesis imperfecta. Fracture was treated with splinting of thigh to abdomen in hyperflexion at hip with slight abduction and external rotation (Fig. 2). Follow-up after 2 weeks was done with repeat X-ray done showing callus formation at fracture ends, complete fracture union was seen at 4 weeks, and splintage was removed (Fig. 3). Clinical examination done showing no tenderness, no

(c) The Author(s). 2020 Open Access This article is distributed under the terms of the Creative Commons Attribution 4.0 International License (https://creativecommons. org/licenses/by-nc/4.0/), which permits unrestricted use, distribution, and non-commercial reproduction in any medium, provided you give appropriate credit to the original author(s) and the source, provide a link to the Creative Commons license, and indicate if changes were made. The Creative Commons Public Domain Dedication waiver (http://creativecommons.org/publicdomain/zero/1.0/) applies to the data made available in this article, unless otherwise stated. 


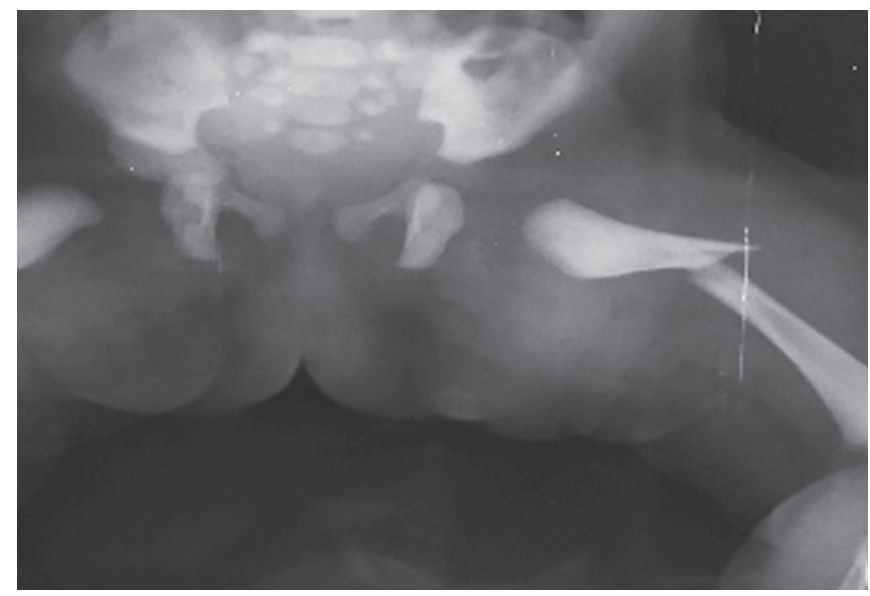

Fig. 1: At birth

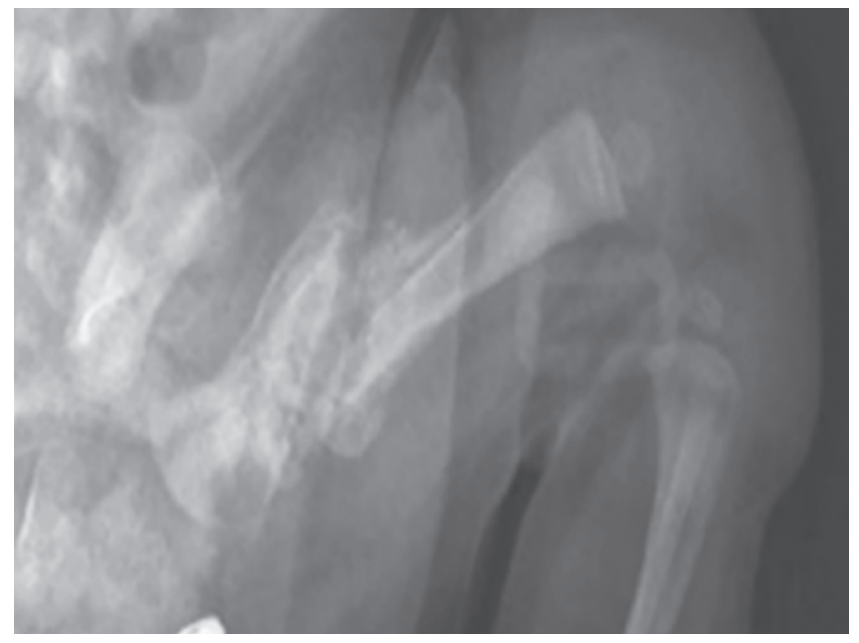

Fig. 3: At 4 weeks

limb length discrepancy, no visible deformity, and active painless limb movements present. Twenty weeks after the birth, both lower limbs were showing a full mobility without any type of any dysmetria (Fig. 4).

\section{Discussion}

These types fractures in newborns are usually result of significant mechanical forces at any point of time in the series of events in childbirth. Risk factors associated with femur fractures in newly born babies are following: both large and very small fetuses, breech presentation, difficult delivery, inadequate uterine relaxation, small uterine incision, twin pregnancies, prematurity, the advanced age of the mother, primipara status, osteogenesis imperfecta, and osteoporosis. ${ }^{6}$ During vaginal delivery, the most common type of fractures almost always involves the clavicle, humerus, and femur. ${ }^{7}$ Fracture of femur has been described with difficult deliveries and is considered rare in newly born babies. ${ }^{1}$ Ehrenfest was the first to describe a fracture of the femur in a newborn associated with a difficult breech extraction during cesarean section in the year 1922. ${ }^{3}$ The chances of femur fracture are significantly reduced in abdominal breech delivery when compared to vaginal delivery, where chances are very high. If the infant is improperly held by one thigh during delivery of the shoulders and arms or excessive

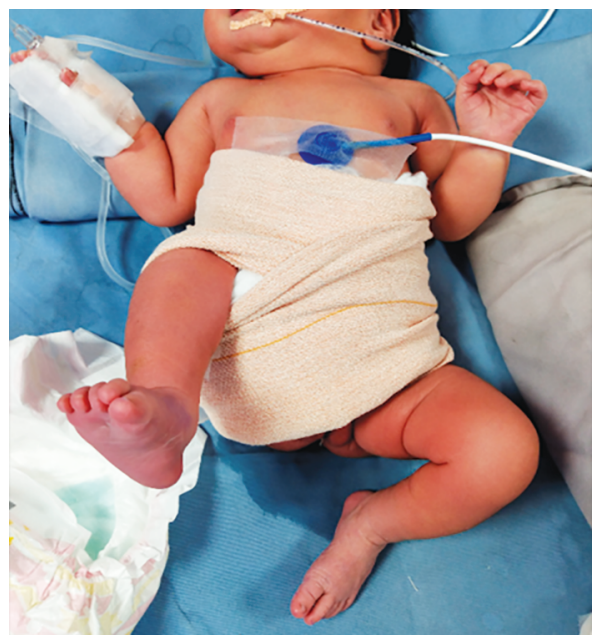

Fig. 2: Treatment

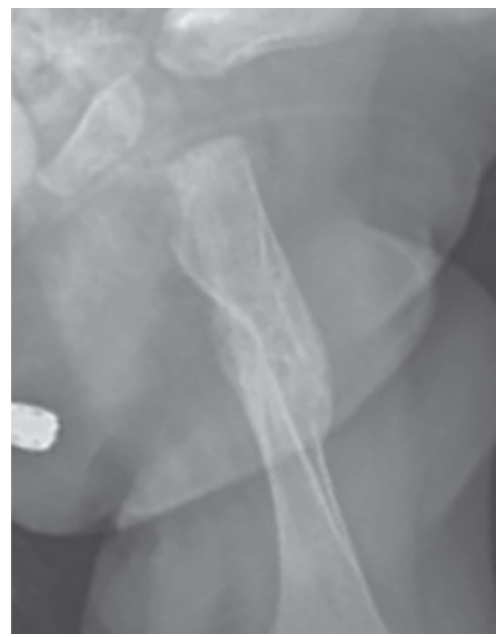

Fig. 4: At 20 weeks

and sudden twisting and pulling maneuver or traction is applied, it might result in such fractures. ${ }^{8}$

As described by Jain and Bielski, history of cesarean section does not completely rule out the possibility of a fracture. ${ }^{9}$ The femoral shaft fractures that occurred during cesarean section were total seven in number as described by Vasa and Kim. ${ }^{10}$ The orthopedics literature recommend these treatment methods for femur fractures in neonates which include posterior splinting, Spica cast, cast in flexion and abduction, gallows traction, Bryant traction and Pavlik harness.

The proximal fragment of fractured femur is flexed, abducted, and externally rotated in the case of subtrochanteric fracture of femur.

\section{Conclusion}

Femur fracture following vaginal delivery in breech presentation is rare but possible condition, cesarean delivery does not eliminate this possible accidental complication but might reduce the risk of causing a traumatic injury of the newborn compared to vaginal delivery, especially with breech presentation. In our case, splinting of right lower limb with abdomen was done in hip hyperflexion, abduction, and external rotation shows complete healing following immobilization. 


\section{References}

1. Morris S, Cassidy N, Stephens M, et al. Birth-associated femoral fractures: incidence and outcome. J Pediatr Orthop 2002;22(1):27-30. DOI: 10.1097/01241398-200201000-00007.

2. Curran JS. Birth associated injury. 5. Clin Perinatol 1981;8(1):111-129. DOI: 10.1016/S0095-5108(18)31099-6.

3. Ehrenfest H. Birth Injuries of the Child. New York, USA: AppletonCentury Crofts; 1922.

4. Canpolat FE, Köse A, Yurdakök M. Bilateral humerus fracture in a neonate after cesarean delivery. Arch Gynecol Obstet 2010;281(5):967-969. DOI: 10.1007/s00404-009-1256-0.

5. Caviglia H, Garrido CP, Palazzi F, et al. Pediatric fractures of the humerus. Clin Orthop Relat Res 2005(432):49-56. DOI: 10.1097/01. blo.0000156452.91271.fb.
6. Awwad JT, Nahhas DE, Karam KS. Femur fracture during cesarean breech delivery. Int J Gynaecol Obstet 1993;43(3):324-326. DOI: 10.1016/0020-7292(93)90524-Z.

7. Kellner KR. Neonatal fracture and cesarean section. Am J Dis Child 1992;136:865.

8. Matsubara S, Izumi A, Nagai T, et al. Femur fracture during abdominal breech delivery. Arch Gynecol Obstet 2008;278(2):195-197. DOI: 10.1007/s00404-008-0655-y.

9. Jain R, Bielski RJ. Fracture of lower femoral epiphysis in an infant at birth: a rare obstetrical injury. J Perinatol 2001;21(8):550-552. DOI: 10.1038/sj.jp.7210540.

10. Vasa R, Kim MR. Fracture of the femur at cesarean section: case report and review of literature. Am J Perinatol 1990;7(01):46-48. DOI: 10.1055/s-2007-999445. 